\title{
Effects of Ni Content and Ball Milling Time on the Hydrogen Storage Thermodynamics and Kinetics Performances of La-Mg-Ni Ternary Alloys
}

\author{
Zhen-Yang $\mathrm{Li}^{1,3}$. Sheng-Li Li ${ }^{1} \cdot$ Ze-Ming Yuan ${ }^{2,3} \cdot$ Yang-Huan Zhang ${ }^{2,3}$
}

Received: 31 August 2018 / Revised: 18 November 2018 / Published online: 27 February 2019

(c) The Chinese Society for Metals (CSM) and Springer-Verlag GmbH Germany, part of Springer Nature 2019

\begin{abstract}
The effects of $\mathrm{Ni}$ content and ball milling time on the hydrogen storage thermodynamics and kinetics performances of asmilled $\mathrm{La}_{5} \mathrm{Mg}_{95_{-}} \mathrm{Ni}_{x}(x=5,10,15)$ ternary alloys have been investigated. The evolution of microstructure and phase of experimental alloys in the absorption/desorption process has been characterized by XRD, SEM and HRTEM. The hydrogen storage kinetics and thermodynamics performances and PCI curves have been tested using the Sievert apparatus. It is found that the rising of $\mathrm{Ni}$ content remarkably improves the hydrogen storage kinetic performance, but reduces hydrogen storage capacity. And with the increase in milling time, hydrogen desorption activation $\left(E_{\mathrm{a}}\right)$ value decreases firstly and then increases; the minimum value is $47.6 \mathrm{~kJ} / \mathrm{mol}$, and the corresponding milling time is $10 \mathrm{~h}$ for $\mathrm{La}_{5} \mathrm{Mg}_{85} \mathrm{Ni}_{10}$ alloy. As for the thermodynamics properties, the hydrogenation enthalpy $(\Delta H)$ and hydrogenation entropy $(\Delta S)$ both decrease firstly and then increase with the rising of $\mathrm{Ni}$ content and milling time. The composite $\mathrm{La}_{5} \mathrm{Mg}_{85} \mathrm{Ni}_{10}$ alloy milled for $10 \mathrm{~h}$ exhibits the best thermodynamics and kinetics performances, the lowest $E_{\mathrm{a}}$ of $47.6 \mathrm{~kJ} / \mathrm{mol}$, absorption of $5.4 \mathrm{wt} . \%$ within 5 min and desorption of $5.2 \mathrm{wt} . \%$ within $3 \mathrm{~min}$ at $360^{\circ} \mathrm{C}$ and the lowest $\Delta H$ and $\Delta S$ of $72.1 \mathrm{~kJ} / \mathrm{mol}$ and $123.2 \mathrm{~J} / \mathrm{mol} / \mathrm{K}$.
\end{abstract}

Keywords Hydrogen storage $\cdot$ Mg-based alloys $\cdot$ Thermodynamics and kinetics $\cdot$ Ni content $\cdot$ Milling time

\section{Introduction}

Hydrogen energy is a clean, efficient, safe, abundant and sustainable ideal secondary energy [1-3], and hydrogen storage technology is the most critical part of the entire hydrogen energy development and application. Hydrogen storage refers to confining hydrogen in a certain form (molecular state, atomic state or ionic state) within a volume and mass

Available online at http://link.springer.com/journal/40195

Yang-Huan Zhang

zhangyh59@sina.com

Sheng-Li Li

lishengli@sdu.cn

1 School of Materials Science and Engineering, Shandong University, Jinan 250061, China

2 Key Laboratory of Integrated Exploitation of Baiyun Obo Multi-Metal Resources, Inner Mongolia University of Science and Technology, Baotou 014010, China

3 Department of Functional Material Research, Central Iron and Steel Research Institute, Beijing 100081, China that fits the actual application and achieving a suitable volumetric energy density and mass energy density $[4,5]$. The application of hydrogen energy and hydrogen storage technology is currently very important in the world. $\mathrm{Mg}$ and $\mathrm{Mg}$ based alloys have become one of the most attractive hydrogen storage material due to their high hydrogen capacity (7.6 wt.\% for $\mathrm{MgH}_{2}, 3.6$ wt.\% for $\mathrm{Mg}_{2} \mathrm{NiH}_{4}$ ) and abundant reserves [6]. Nevertheless, it also has many flaws, such as high dehydrogenation temperature, sluggish hydrogen storage kinetics and poor electrochemical cycle stability, which seriously affected their practical development $[7,8]$. Scientists have made many attempts to elevate the performances of Mg-based alloys, such as alloying [9], catalysis [10], ball milling [11] and rapid solidification [12]. In this paper, we will focus on the effects of alloying and ball milling on asmilled $\mathrm{La}_{5} \mathrm{Mg}_{95-x} \mathrm{Ni}_{x}(x=5,10,15)$ ternary alloys which are a new type of $\mathrm{Mg}$-based alloys.

As for the method of alloying, $\mathrm{Re}-\mathrm{Mg}-\mathrm{Ni}$ alloys have been reported as the high-profile materials with excellent performance. Oesterreicher et al. [13] prepared the $\mathrm{La}_{1-x} \mathrm{Mg}_{x} \mathrm{Ni}_{2}$ alloy by induction melting method for the first time, which opened up the research field of $\mathrm{Re}-\mathrm{Mg}-\mathrm{Ni}$-based 
hydrogen storage materials. The $\mathrm{La}_{0.33} \mathrm{Mg}_{0.67} \mathrm{Ni}_{2}$ alloy can form its hydrides at room temperature. According to related reports, $\mathrm{Re}-\mathrm{Mg}-\mathrm{Ni}$ alloys have good capacities and excellent hydrogen absorption/desorption properties [14-17]. For example, Zhang et al. [18] comprehensively reported the melt-spun Mg10NiLa specimens show an amorphous phase and minor crystalline $\mathrm{La}_{2} \mathrm{Mg}_{17}$ after melt-spinning. Siarhei et al. [19-21] prepared many types of $\mathrm{Re}-\mathrm{Mg}-\mathrm{Ni}$ alloys and obtained good reversible capacities. For example, he prepares $\mathrm{Mg}_{90} \mathrm{Ni}_{8} \mathrm{RE}_{2}(\mathrm{Re}=\mathrm{Y}, \mathrm{Nd}, \mathrm{Gd})$ and obtained a hydrogen storage capacity of $5.6 \mathrm{wt} . \%$, prepared melt-spun $\mathrm{Mg}-\mathrm{Ni}-\mathrm{Cu}-\mathrm{Y}$ and obtained a hydrogen absorption capacity of 4.8 wt.\%, prepared $\mathrm{Mg}_{80} \mathrm{Ni}_{10} \mathrm{Y}_{10}$ and obtained a reversible hydrogen capacity of $5.2 \mathrm{wt} \%$. Gu et al. [22] prepared $\mathrm{Mg}_{88.5} \mathrm{Ni}_{x} \mathrm{La}_{y}(y / x=1 / 16)$ alloys and obtained a hydrogen storage capacity of $4.45 \mathrm{wt}$.\%. Lv et al. [23] reported microstructural evolution of $\mathrm{Mg}-x \mathrm{Ni}-3 \mathrm{La}(x=5,10,15,20$ at.\%) alloys; $\mathrm{Mg}-15 \mathrm{Ni}-3 \mathrm{La}$ alloy shows the lowest $E_{\mathrm{a}}$ of $80.36 \mathrm{~kJ} /$ mol. Yuan et al. [24] reported the $\mathrm{Mg}-10 \mathrm{Ni}-x \mathrm{Mm}(x=1,2$, 3 at.\%) alloys which are obtained using a simple one-step method of induction melting. The materials can absorb 5.26 wt. $\% \mathrm{H}_{2}$ in $350 \mathrm{~s}$ at $300{ }^{\circ} \mathrm{C}$ and desorb $4.72 \mathrm{wt} . \%$ in $300 \mathrm{~s}$ at $300{ }^{\circ} \mathrm{C}$. The $E_{\mathrm{a}}$ value of $\mathrm{MgH}_{2}$ decreases to $88.6 \mathrm{~kJ} / \mathrm{mol}$. It can be seen that $\mathrm{Re}-\mathrm{Mg}-\mathrm{Ni}$ alloys have good hydrogen storage capacities and low $E_{\mathrm{a}}$ value, which deserves further study. However, $\mathrm{La}_{5} \mathrm{Mg}_{95_{-}-x} \mathrm{Ni}_{x}(x=5,10,15)$ ternary alloys have never been mentioned in the literature of the past, and the addition of rare earth La element can enhance hydrogen storage performance, and their hydrogen storage properties with different $\mathrm{Ni}$ contents are of great interest.

Generally, in the field of hydrogen storage, ball milling technique can be utilized to decrease the crystallite size, particle size, defects and distribution of catalyst, and the ball milling time is thought as a key factor [25, 26]. For example, Liu et al. [27] studied the effects of milling times (from 0.5 to $18 \mathrm{~h}$ ) on the dehydrogenation properties of $\mathrm{LiAlH}_{4}$ catalyzed by $\mathrm{TiF}_{3}$. With rising of milling times, the crystallite sizes of $\mathrm{LiAlH}_{4}$ get smaller and the dehydrogenation properties are improved. Wu et al. [28] studied the hydrogen storage properties of mechanochemically prepared $\mathrm{MgH}_{2} /$ single-walled carbon nanotube (SWNT) materials. The composite $\mathrm{MgH}_{2} / 5 \mathrm{wt}$. $\%$ SWNTs milled for $10 \mathrm{~h}$ showed the best properties. However, it shows a serious degradation on all aspects of performances when milling time is over $10 \mathrm{~h}$. Chu et al. [29] studied the influence of milling time on the structure and electrochemical performances of $\mathrm{La}-\mathrm{Mg}-\mathrm{Ni}$ based materials. With the rising of milling time, cyclic life of them can be elevated, especially for the compound milled for $2 \mathrm{~h}$. Zhang et al. [30] studied nanocrystalline/ amorphous $\mathrm{LaMg}_{11} \mathrm{Ni}+x \% \mathrm{Ni}(x=100,200$, mass fraction) alloys by ball milling and found that proper milling time visibly improves the gaseous hydrogen storage properties. It can be seen that ball milling is an efficient way to elevate the hydrogen storage performance and milling time which is able to be seen as the key factor. Therefore, we choose ball milling to improve the hydrogen storage performance of $\mathrm{La}_{5} \mathrm{Mg}_{95-x} \mathrm{Ni}_{x}(x=5,10,15)$ alloy.

Liu et al. [31] reported that $\mathrm{Mg}_{100-x} \mathrm{Ni}_{x}(x=5,11.3,20$, 25 ) specimens show excellent hydrogen storage properties, but not considering the alloying method and ball milling methods. Considering the addition of rare earth La element and proper ball milling time can enhance hydrogen storage performance, the target materials were determined to be as-milled $\mathrm{La}_{5} \mathrm{Mg}_{95-x} \mathrm{Ni}_{x}(x=5,10,15)$. In this paper, the effects of Ni content and ball milling time on the hydrogen storage thermodynamics and kinetics performances of asmilled $\mathrm{La}_{5} \mathrm{Mg}_{95-x} \mathrm{Ni}_{x}(x=5,10,15)$ ternary alloys have been systematically investigated.

\section{Experimental}

The vacuum induction furnace was utilized to prepare the $\mathrm{La}_{5} \mathrm{Mg}_{95-x} \mathrm{Ni}_{x}(x=5,10,15)$ ternary alloys and for preventing $\mathrm{Mg}$ volatilizing; the furnace was put in a helium atmosphere. In these preparation conditions, putting excess $\mathrm{Mg}(10 \%)$ and $\mathrm{La} \mathrm{(5 \% )}$ is crucial to compensate for evaporative loss based on our experience. After the alloys were melted, insulation for 10 min made them well mixed, and then molten alloy is poured into a copper cooled mold. On cooling them to room temperature, a cast ingot was obtained. Then the as-cast alloy powders were mechanically ball milled for 5, 10, 20, $30 \mathrm{~h}$ with $350 \mathrm{rpm}$ speed under Ar atmosphere in a planetary-type mill. The weight ratio of the powders and $\mathrm{Cr}-\mathrm{Ni}$ stainless steel balls was 1:40. To prevent excess heating, the mill was set to rest for $0.5 \mathrm{~h}$ after every $0.5 \mathrm{~h}$ working during this process.

The phase structures and morphologies of the as-milled $\mathrm{La}_{5} \mathrm{Mg}_{95_{-} x} \mathrm{Ni}_{x}(x=5,10,15)$ ternary alloys are determined by X-ray diffraction (XRD) $(D / \max / 2400)$, Philips SEM (QUANTA 400) and HRTEM (JEM-2100F, operated at $200 \mathrm{kV})$.

The PCI curves, hydrogen absorption/desorption kinetics of $\mathrm{La}_{5} \mathrm{Mg}_{95-x} \mathrm{Ni}_{x}(x=5,10,15)$ ternary alloys, were measured by an automatically controlled Sieverts apparatus with a furnace controlled to an accuracy of $\pm 1{ }^{\circ} \mathrm{C} .0 .5 \mathrm{~g}$ sample which is passed through a 300-mesh sieve was put into a cylindrical reactor in every experiment. The hydrogen absorption was conducted at an initial $\mathrm{H}_{2}$ pressure of $3.5 \mathrm{MPa}$ at 100, 150, 200, 220, 240, 260, 280, 300, 320, 340 and $360^{\circ} \mathrm{C}$ and the hydrogen desorption at an initial $\mathrm{H}_{2}$ pressure of $1 \times 10^{-4} \mathrm{MPa}$ at $280,300,320,340$ and $360^{\circ} \mathrm{C}$. After every experiment, the temperature was reset to $360^{\circ} \mathrm{C}$, and the sample chamber was evacuated below $1 \times 10^{-4} \mathrm{MPa}$ for $30 \mathrm{~min}$ to make sure the hydrogen be released completely. 
For ease of writing, $\mathrm{La}_{5} \mathrm{Mg}_{95-x} \mathrm{Ni}_{x}(x=5,10,15)$ alloys are abbreviated as Ni5, Ni10, Ni15.

\section{Results and Discussion}

\subsection{Crystal and Microstructural Characteristics}

The XRD patterns of as-milled $\mathrm{La}_{5} \mathrm{Mg}_{95-x} \mathrm{Ni}_{x}(x=5,10,15)$ ternary alloys can be seen from Fig. 1. From Fig. 1a, it is indicated that the Ni5, Ni10, Ni15 alloys milled for $5 \mathrm{~h}$ are all based on $\mathrm{La}_{2} \mathrm{Mg}_{17}$ as main phase, $\mathrm{Mg}_{2} \mathrm{Ni}$ and $\mathrm{Mg}$ as second phases. Moreover, it shows that the amount of $\mathrm{Mg}_{2} \mathrm{Ni}$ phase visibly increases with the rising of $\mathrm{Ni}$ content. From Fig. 1b, the XRD patterns of Ni10 alloys with different milling times are shown. It indicates that the diffraction peaks of these alloys are obviously broadened, which are typical nanocrystalline and polycrystalline diffraction characteristics. As the milling time extended, the diffraction peak of $\mathrm{La}_{2} \mathrm{Mg}_{17}$ phase is gradually broadened when milled for $5 \mathrm{~h}$. However, the diffraction peak of the $\mathrm{Mg}_{2} \mathrm{Ni}$ phase remained stable, and no significant change occurred even after milling for $30 \mathrm{~h}$. It indicated that the ball milling process has a significant effect on $\mathrm{La}_{2} \mathrm{Mg}_{17}$ phase. Ball milling leads to the nanocrystallization of the $\mathrm{La}_{2} \mathrm{Mg}_{17}$ main phase, and an amorphous structure may occur even with the rising of ball milling time.

The SEM images of the as-milled Ni10 powders are shown in Fig. 2. Ni10 alloys are shown as representative. It can be clearly seen from the pictures that as the milling time increases, the particles become significantly diminish, greatly increasing the surface area in contact with $\mathrm{H}_{2}$ and improving the hydrogen storage performance. HRTEM micrographs and ED patterns of the as-milled Ni10 alloys with different milling time are shown in Fig. 3. The areas shown in the images are randomly selected to calibrate the lattice phase. It is obvious that the phase structure of the Ni10 alloy milled for $5 \mathrm{~h}$ has a large amount of nanocrystallization areas. Figure $3 \mathrm{~b}$ shows that the sizes and amounts of nanocrystallites gradually increase and the nanocrystallization areas appear in the meantime as the ball milling time increases to $10 \mathrm{~h}$. As shown in Fig. 3d, the large amorphous regions appear when the milling time extended to $30 \mathrm{~h}$, and their size can reach 10-20 $\mathrm{nm}$. The phenomenon of nanocrystal crystallization increases the number of grain boundaries, and the grain boundaries are channels which act as hydrogen diffusion, and the nano-interfaces can store a part of hydrogen. Therefore, nanocrystallization can improve the hydrogen storage performances of Mg-based alloys. Amorphous area also provides a certain interface to promote the diffusion of hydrogen, but it cannot have the ability to store hydrogen. Therefore, a small amount of amorphous is also beneficial for improving the hydrogen storage kinetics, but it will significantly reduce the hydrogen storage properties if the amorphous amounts are excessive.

\subsection{Hydrogen Storage Kinetics}

The isothermal hydrogen absorption kinetic curves of asmilled alloys at $360{ }^{\circ} \mathrm{C}$ and $100{ }^{\circ} \mathrm{C}$ are shown in Fig. 4. With more than six activation cycles, the Ni5, Ni10, Ni15 alloys milled for $5 \mathrm{~h}$ have $5.61 \mathrm{wt} . \%, 5.15 \mathrm{wt} . \%, 4.50 \mathrm{wt} . \%$ hydrogen absorption capacity within $300 \mathrm{~s}$, as seen from Fig. 4a. However, the Ni5, Ni10 and Ni15 alloys milled for 5 h have
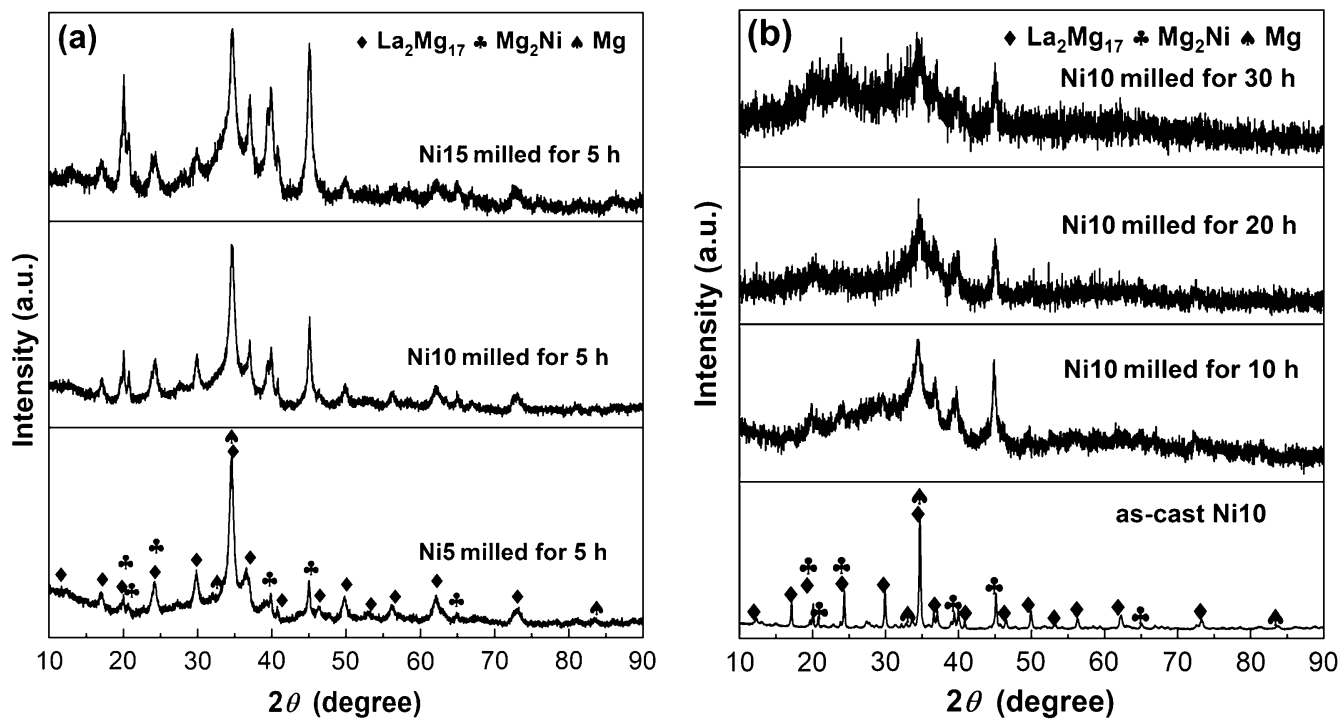

Fig. 1 XRD profiles of as-milled $\mathrm{La}_{5} \mathrm{Mg}_{95-x} \mathrm{Ni}_{x}(x=5,10,15)$ alloys: a Ni5, Ni10, Ni15 alloys milled for 5 h; b Ni10 alloys with different milling times 


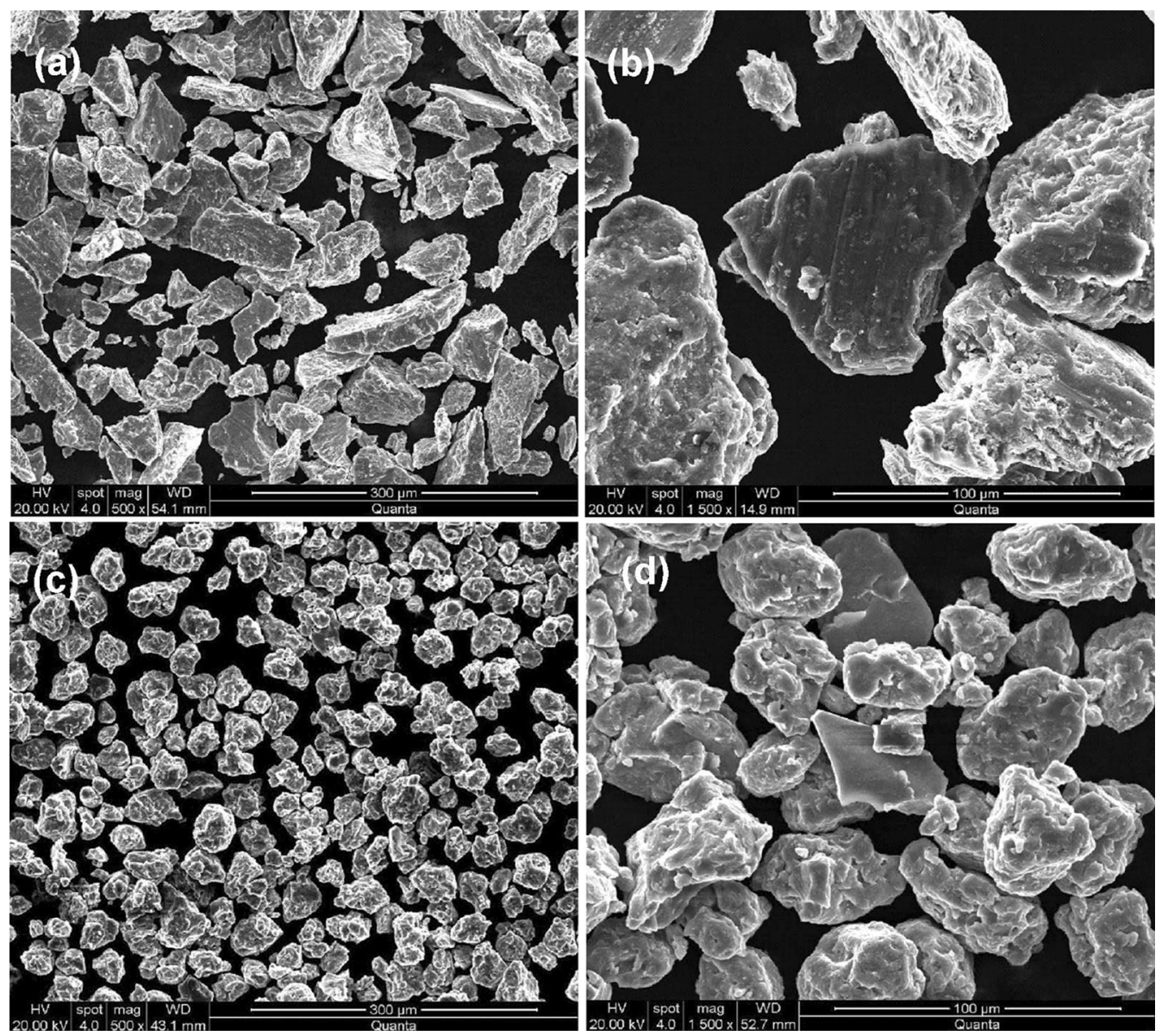

Fig. 2 SEM images of Ni10 alloys: a, b as-cast Ni10 alloy; $\mathbf{c}, \mathbf{d}$ Ni10 alloy milled for $10 \mathrm{~h}$

4.26 wt. $\%, 4.30$ wt. $\%, 3.51$ wt.\% hydrogen absorption capacity in $25 \mathrm{~min}(1500 \mathrm{~s})$ at $100{ }^{\circ} \mathrm{C}$, respectively. From Fig. 4c, the Ni10 alloy can absorb $5.01 \mathrm{wt} \%$ when as-cast, $5.15 \mathrm{wt} . \%$ when milled for $5 \mathrm{~h}, 5.37 \mathrm{wt} . \%$ when milled for $10 \mathrm{~h}, 5.11$ wt.\% when milled for $20 \mathrm{~h}$ and $4.71 \mathrm{wt} \%$ when milled for $30 \mathrm{~h}$ within $300 \mathrm{~s}$ at $360{ }^{\circ} \mathrm{C}$, respectively. From Fig. $4 \mathrm{~d}$, the Ni10 alloy can absorb $4.10 \mathrm{wt} \%$ when as-cast, $4.30 \mathrm{wt} \%$ when milled for $5 \mathrm{~h}, 4.67 \mathrm{wt} \%$ when milled for $10 \mathrm{~h}, 4.20$ wt.\% when milled for $20 \mathrm{~h}$ and $3.36 \mathrm{wt} \%$ when milled for $30 \mathrm{~h}$ within $25 \mathrm{~min}(1500 \mathrm{~s})$ at $100{ }^{\circ} \mathrm{C}$, respectively.

The isothermal hydrogen desorption kinetic curves at $360{ }^{\circ} \mathrm{C}$ and $280{ }^{\circ} \mathrm{C}$ are shown in Fig. 5. With more than six activation cycles, the as-milled Ni5, Ni10, Ni15 alloys can desorb 5.59 wt. \% within 210 s, 5.07 wt.\% within 156 s, 4.57 wt.\% within $96 \mathrm{~s}$ at $360{ }^{\circ} \mathrm{C}$, respectively. In Fig. 5b, the asmilled Ni5, Ni10, Ni15 alloys can desorb 5.40 wt.\% within 2010 s, 4.71 wt.\% within 702 s, 4.45 wt.\% within 444 s at $280{ }^{\circ} \mathrm{C}$, consistent with the law of hydrogen absorption process. The capacity reduces with the rising of Ni content, but the rate of hydrogen desorption process visibly elevates in the experimental range. From Fig. 5c, the Ni10 alloys with different milling times can desorb approximately $5.15 \mathrm{wt} . \%$ within $175 \mathrm{~s}$ at $360{ }^{\circ} \mathrm{C}$. It can be seen that the hydrogen desorption rate of $\mathrm{Ni} 10$ milled for $10 \mathrm{~h}$ is the fastest, followed by $5 \mathrm{~h}, 20 \mathrm{~h}$ and as-cast, Ni10 milled for $30 \mathrm{~h}$ reaches the slowest rate of hydrogen desorption. From Fig. 5d, the Ni10 alloys with different milling times can desorb approximately 4.8 wt. $\%$ within $700 \mathrm{~s}$ at $280{ }^{\circ} \mathrm{C}$. The results agree with the situation obtained at $360{ }^{\circ} \mathrm{C}$, indicating that $\mathrm{Ni10}$ alloys milling for 5 and $10 \mathrm{~h}$ can significantly improve the hydrogen desorption performance, which may be attributed to the fact that the nanocrystalline structure produced by ball milling provides many channels for hydrogen diffusion, thus improving the kinetic properties of hydrogen absorption/desorption reaction.

To facilitate comparison of hydrogen absorption/desorption rates, the new variables have been defined, $C_{t}^{\mathrm{a} / \mathrm{d}}$ and $R_{t}^{\mathrm{a} / \mathrm{d}}$ (where a represents the hydrogen absorption process and $d$ represents the hydrogen desorption process). $C_{t}^{\mathrm{a} / \mathrm{d}}$ is utilized to represent the amounts of $\mathrm{H}_{2}$ absorbed by the material at time $t$, and $R_{t}^{\mathrm{a} / \mathrm{d}}$ is utilized to represent the ratio of the amounts of $\mathrm{H}_{2}$ absorbed by the material at time $t$ and the maximum hydrogen absorption/desorption amounts $\left(R_{t}^{\mathrm{a} / \mathrm{d}}=C_{t}^{\mathrm{a} / \mathrm{d}} / C_{\max }^{\mathrm{a} / \mathrm{d}} \times 100 \%\right)$. In particular, we select 

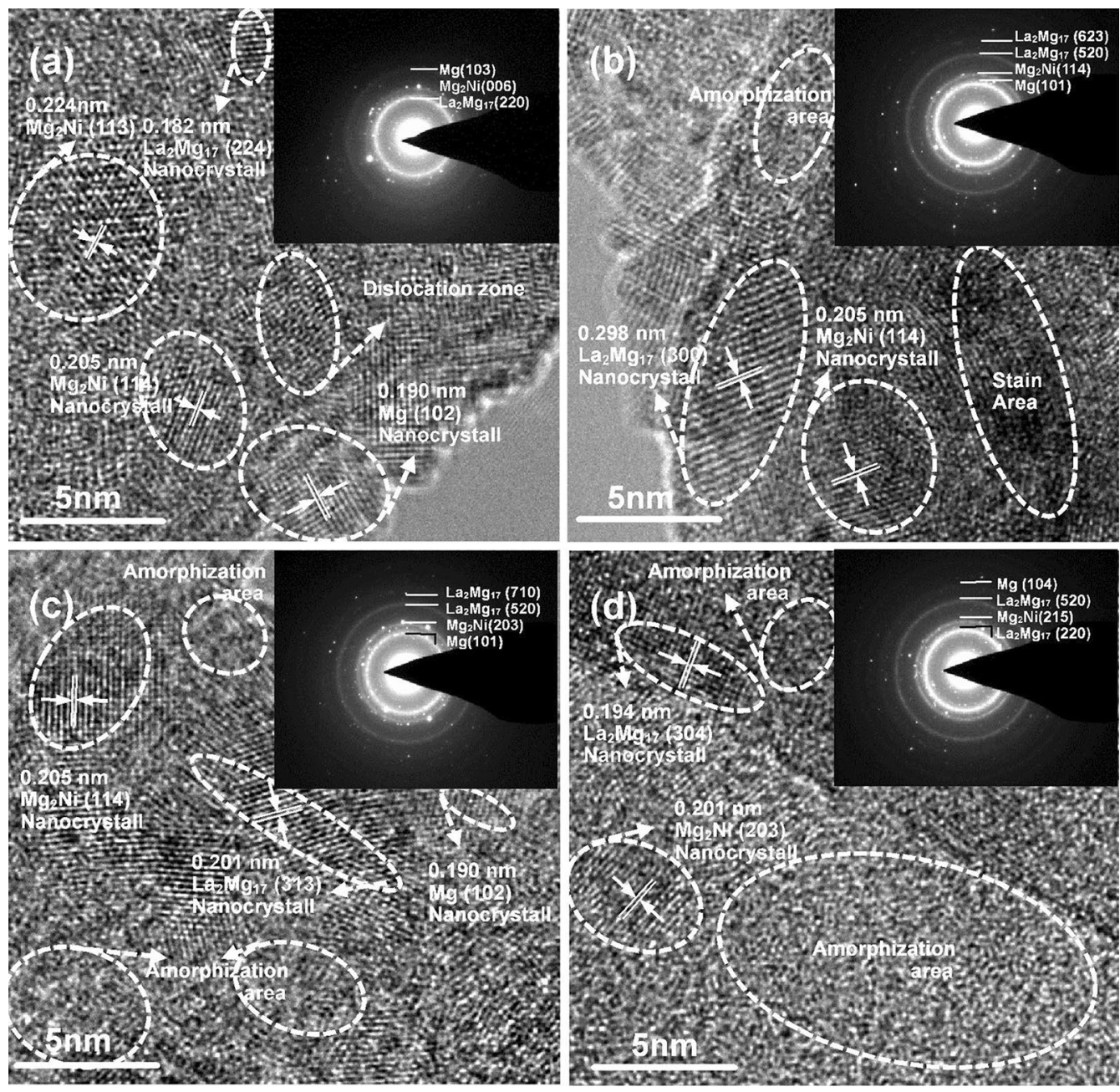

Fig. 3 HRTEM micrographs and ED patterns of the as-milled Ni10 alloys with different milling times: a $5 \mathrm{~h}$; b $10 \mathrm{~h}$; c $20 \mathrm{~h}$; d $30 \mathrm{~h}$

one-sixth of the total hydrogen absorption/desorption time (50 s for $360^{\circ} \mathrm{C}$ and $250 \mathrm{~s}$ for $100^{\circ} \mathrm{C}$ during the absorption process, $42 \mathrm{~s}$ for $360^{\circ} \mathrm{C}$ and $360 \mathrm{~s}$ for $100^{\circ} \mathrm{C}$ during the desorption process) and mark it as $R_{*}^{\mathrm{a} / \mathrm{d}}$ to compare the hydrogen absorption/desorption rate of the alloys. As shown in Fig. 6a, c, it can be clearly seen that the absorption/desorption rate of Ni5 is the slowest, followed by Ni10, and the fastest is Ni15. It is obvious that rate of hydrogen absorption/desorption process elevates with the rising of $\mathrm{Ni}$ content because $\mathrm{Mg}$ has a greater hydrogen storage capacity and slower absorption/desorption rate than $\mathrm{Mg}_{2} \mathrm{Ni}$. From Fig. 6b, d, it is can be clearly seen that $\mathrm{Ni} 10$ milled for $10 \mathrm{~h}$ has the fastest hydrogen absorption/desorption rate and the largest hydrogen storage capacity, followed by $5 \mathrm{~h}, 20 \mathrm{~h}$ and as-cast and Ni10 milled for $30 \mathrm{~h}$ exhibits the slowest hydrogen absorption/desorption rate and the capacity. With the increase in milling time, the hydrogen absorption/desorption rate and capacity of alloys increase firstly and then decreases because the nanocrystalline phases appear after milling for $5 \mathrm{~h}$, and they can visibly elevate the hydrogen storage performance due to the high-density grain boundary of nanocrystalline which can increase amounts of fast hydrogen diffusion channels as well as reduce the dissociation energy of $\mathrm{H}_{2}$ on their surfaces. However, as milling times elevates, the amorphous phases cannot react with $\mathrm{H}_{2}$ and produce hydride, and then, the hydrogen storage property is reduced.

As for an important value to characterize the hydrogen storage kinetic, hydrogen desorption activation $\left(E_{\mathrm{a}}\right)$, we utilized Johnson-Mehl-Avrami (JMA) model to simulate the curves and Arrhenius method to calculate it. Then, the influence of $\mathrm{Ni}$ content and ball milling time on the hydrogen storage kinetics can be obtained from it. In general, activation energy is seen as an obstacle that all potential barriers that perform a gas-solid reaction have to get over it, and it is an extremely decisive part in the gas-solid reaction kinetics. It is widely acknowledged that hydrogen desorption reaction is related to total energy barriers which is considered with hydrogen desorption processes. JMA model can be utilized 

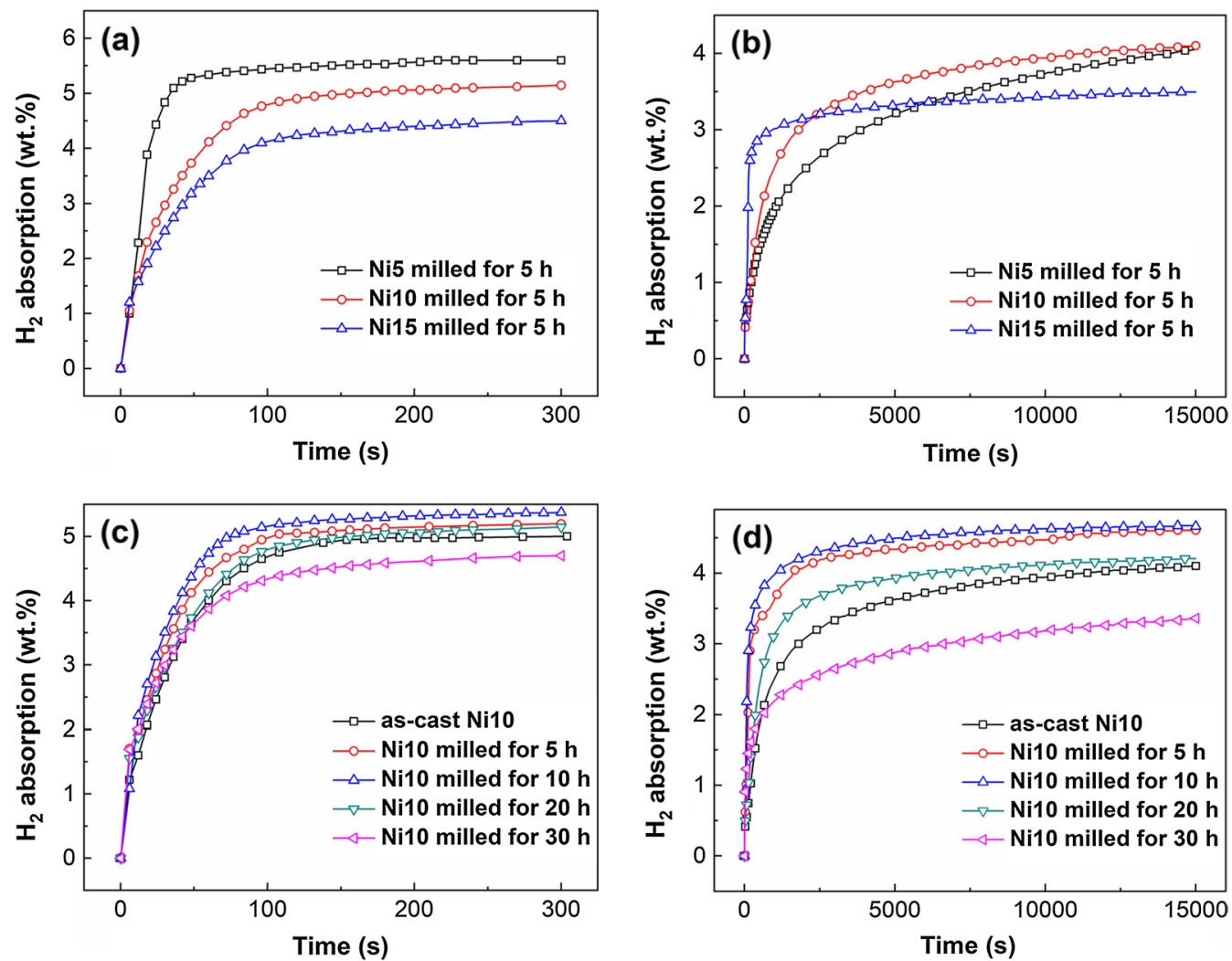

Fig. 4 Hydrogen absorption kinetic curves of as-milled $\mathrm{La}_{5} \mathrm{Mg}_{95-x} \mathrm{Ni}_{x}(x=5,10,15)$ alloys: $\mathbf{a}, \mathbf{b} \mathrm{Ni5}$, Ni10, Ni15 alloys milled for 5 h at $360{ }^{\circ} \mathrm{C}$ and $100^{\circ} \mathrm{C} ; \mathbf{c}, \mathbf{d}$ Ni10 alloys with different milling times at $360{ }^{\circ} \mathrm{C}$ and $100{ }^{\circ} \mathrm{C}$

to simulate nucleation and growth processes of the alloys using Eq. (1) as follows:

$\ln [-\ln (1-\alpha)]=\eta \ln k+\eta \ln t$.

In the equation, $t, \alpha, \eta, k$ characterize the time, the fraction of alloy converted to hydride at time $t$, the Avrami exponent and an effective kinetic parameter. As seen from Fig. 7a, c, Ni10 milled for $5 \mathrm{~h}$ and $20 \mathrm{~h}$ is shown as an example, by using the logarithmic transformation, and the JMA images of $\ln [-\ln (1-\alpha)]$ and $\ln t$ at $300,320,340,360^{\circ} \mathrm{C}$ for the dehydrogenation of the alloys can be obtained. The JMA images are found to be nearly linear; it means that the dehydriding reaction of the alloys abides by instantaneous nucleation which is followed by interface controlled threedimensional growth process. The $k$ value can be obtained from the slope $\eta$ and intercept $\eta \ln k$, and then, Arrhenius methods can be used to calculate the $E_{\mathrm{a}}$ using Eq. (2) as follows:

$k=A \exp \left[-E_{a} /(R T)\right]$.

In the equation, $A, R, T$ characterize a temperatureindependent coefficient, the universal gas constant and an absolute temperature. As seen from Fig. 7b, by utilizing the logarithmic transformation, the Arrhenius images of $\ln k$ and $1 / T$ at $300,320,340,360^{\circ} \mathrm{C}$ for dehydrogenation of the as-milled alloys can be obtained. The Arrhenius images are found to be nearly linear; the $E_{\mathrm{a}}$ values of the alloys can be calculated by the slopes of the line. The $E_{\mathrm{a}}$ values of the Ni5, Ni10, Ni15 milled for $5 \mathrm{~h}$ are calculated to be 67.3, 53.0, $51.6 \mathrm{~kJ} / \mathrm{mol}$, and the hydrogen storage kinetics becomes better with the rising of Ni content, which closely corresponds with the reality. However, as seen in Fig. $7 \mathrm{~d}$, the $E_{\mathrm{a}}$ values are calculated to be $74.1 \mathrm{~kJ} / \mathrm{mol}$ for as-cast, $53.0 \mathrm{~kJ} / \mathrm{mol}$ for $5 \mathrm{~h}, 47.6 \mathrm{~kJ} / \mathrm{mol}$ for $10 \mathrm{~h}, 58.3 \mathrm{~kJ} / \mathrm{mol}$ for $20 \mathrm{~h}$ and $70.1 \mathrm{~kJ} /$ mol for $30 \mathrm{~h}$. With the increase in milling time, the $E_{\mathrm{a}}$ value reduces firstly and then increases, and the minimum value is $47.6 \mathrm{~kJ} / \mathrm{mol}$, and the corresponding milling time is $10 \mathrm{~h}$. The $E_{\mathrm{a}}$ values of as-milled alloys are all lower than those of as-cast alloy, and the variation of $E_{\mathrm{a}}$ is mainly due to the adjustment of microstructure by ball milling process. Therefore, the dehydrogenation activation of Ni10 milled for $10 \mathrm{~h}$ can obtain the lowest $E_{\mathrm{a}}$ value and has the best kinetic performance. The value is greatly lower than $160 \mathrm{~kJ} / \mathrm{mol}$ of the $\mathrm{MgH}_{2}$ [32], $80.36 \mathrm{~kJ} / \mathrm{mol}$ of $\mathrm{Mg}-15 \mathrm{Ni}-3 \mathrm{La}$ alloy [23] and $59.1-78.6 \mathrm{~kJ} / \mathrm{mol}$ of as-milled $\mathrm{LaMg}_{11} \mathrm{Ni}+x \mathrm{Ni}$ alloy [30]. The lower $E_{\mathrm{a}}$ value is mostly due to the alloying, the presence of the rare earth hydride and the ball milling effect. 

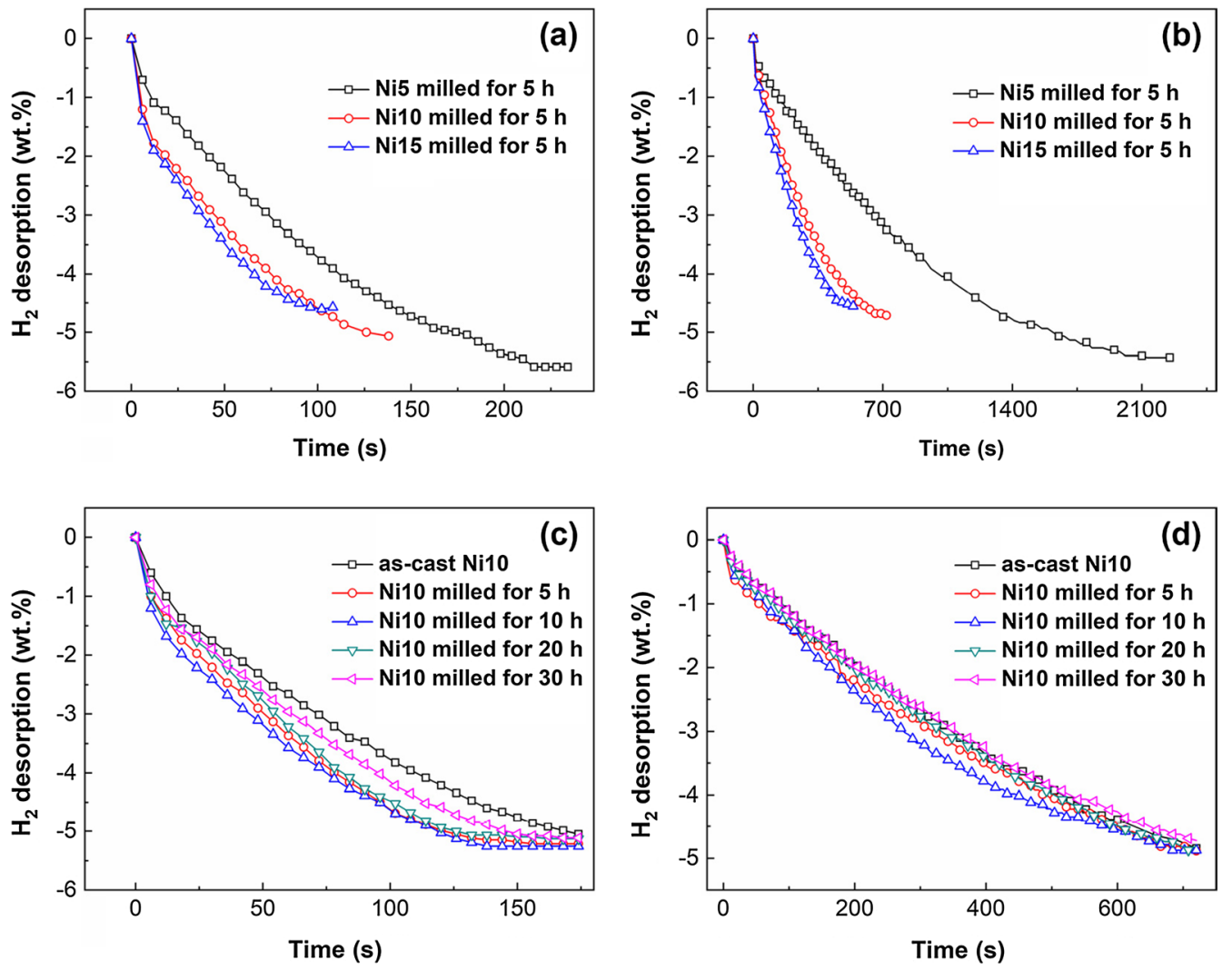

Fig. 5 Hydrogen desorption kinetic curves of as-milled $\mathrm{La}_{5} \mathrm{Mg}_{95-x} \mathrm{Ni}_{x}(x=5,10,15)$ alloys: $\mathbf{a}, \mathbf{b} \mathrm{Ni5}, \mathrm{Ni10}$, Ni15 alloys milled for $5 \mathrm{~h}$ at $360{ }^{\circ} \mathrm{C}$ and $280{ }^{\circ} \mathrm{C} ; \mathbf{c}, \mathbf{d}$ Ni10 alloys with different milling times at $360{ }^{\circ} \mathrm{C}$ and $280{ }^{\circ} \mathrm{C}$

The addition of $\mathrm{Ni}$ causes the alloy to produce more $\mathrm{Mg}_{2} \mathrm{Ni}$ phase, while $\mathrm{Mg}_{2} \mathrm{Ni}$ has a very low hydrogen evolution activation energy although its hydrogen storage capacity is less than $\mathrm{Mg}$. And the addition of rare earth La makes the activated alloy to have a rare earth hydride phase $\mathrm{LaH}_{3}$, and $\mathrm{LaH}_{3}$ has a "hydrogen pump effect", which greatly reduces the hydrogen activation energy value of the alloys. Ball milling is able to transform polycrystalline structures into nanocrystalline and amorphous structures. With the increase in milling time, the phase content of nanocrystals will increase firstly and then decrease. When the milling time reaches $10 \mathrm{~h}$, the alloy is mainly composed of nanocrystalline phases with a large number of sub-grain boundaries, which can maximize the hydrogen absorption and desorption properties of the alloys. Further prolongation of milling time leads to the decrease in nanocrystalline phase and increases amount and size of amorphous phase.

\subsection{Thermodynamic Properties}

The PCI curves of $\mathrm{La}_{5} \mathrm{Mg}_{95-x} \mathrm{Ni}_{x}(x=5,10,15)$ ternary alloys have been tested at $300,320,340,360{ }^{\circ} \mathrm{C}$ to explore the influence of $\mathrm{Ni}$ content and milling times on the thermodynamic property, as seen from Fig. 8. Two distinct hydrogen absorption/desorption plateaus can be easily found in the PCI curves. The reaction at the first absorption plateaus is $\mathrm{Mg}+\mathrm{H}_{2} \rightarrow \mathrm{MgH}_{2}$ and the second is $\mathrm{Mg}_{2} \mathrm{Ni}+\mathrm{H}_{2} \rightarrow \mathrm{Mg}_{2} \mathrm{NiH}_{4}$. And according to the PCI images, the important thermodynamic parameters of $\mathrm{La}_{5} \mathrm{Mg}_{95-x} \mathrm{Ni}_{x}(x=5,10,15)$ ternary alloys, $\Delta H$ and $\Delta S$, are able to be calculated by means of van't Hoff Eq. (3) which is as follows:

$\ln \left[P\left(H_{2}\right) / P_{0}\right]=\Delta H /(R T)-\Delta S / R$.

In the equation, $P\left(\mathrm{H}_{2}\right)$ and $P_{0}$ characterize the equilibrium plateau pressure and $1 \mathrm{~atm}$. As seen from Fig. $8 \mathrm{~b}$, d, the van't Hoff images of $\ln \left[P\left(\mathrm{H}_{2}\right) / P_{0}\right]$ and $1000 / T$ are shown. The Arrhenius images are found to be nearly linear, and the $\Delta H$ and $\Delta S$ values are able to be estimated by the slopes and intercepts of the line. As shown in Fig. 9a, the $\Delta H$ values of $\mathrm{Ni5}, \mathrm{Ni10}$, Ni15 milled for $5 \mathrm{~h}$ are calculated to be -83.4 , $-77.0,-78.6 \mathrm{~kJ} / \mathrm{mol}$, and the $\Delta S$ values of $\mathrm{Ni} 5, \mathrm{Ni} 10$, Ni15 milled for $5 \mathrm{~h}$ are calculated to be $-141.5,-134.8$, $-138.1 \mathrm{~J} / \mathrm{mol} / \mathrm{K}$. It is found that both the $\Delta H$ and $\Delta S$ values decrease firstly and then increase with the rising of Ni content in this range. The excellent performance of as-milled $\mathrm{Ni} 10$ is mostly due to the proper mixing ratio, the microstructure of the alloys and the presence of the rare earth hydride. As seen from Fig. 9b, the $\Delta H$ values are calculated 

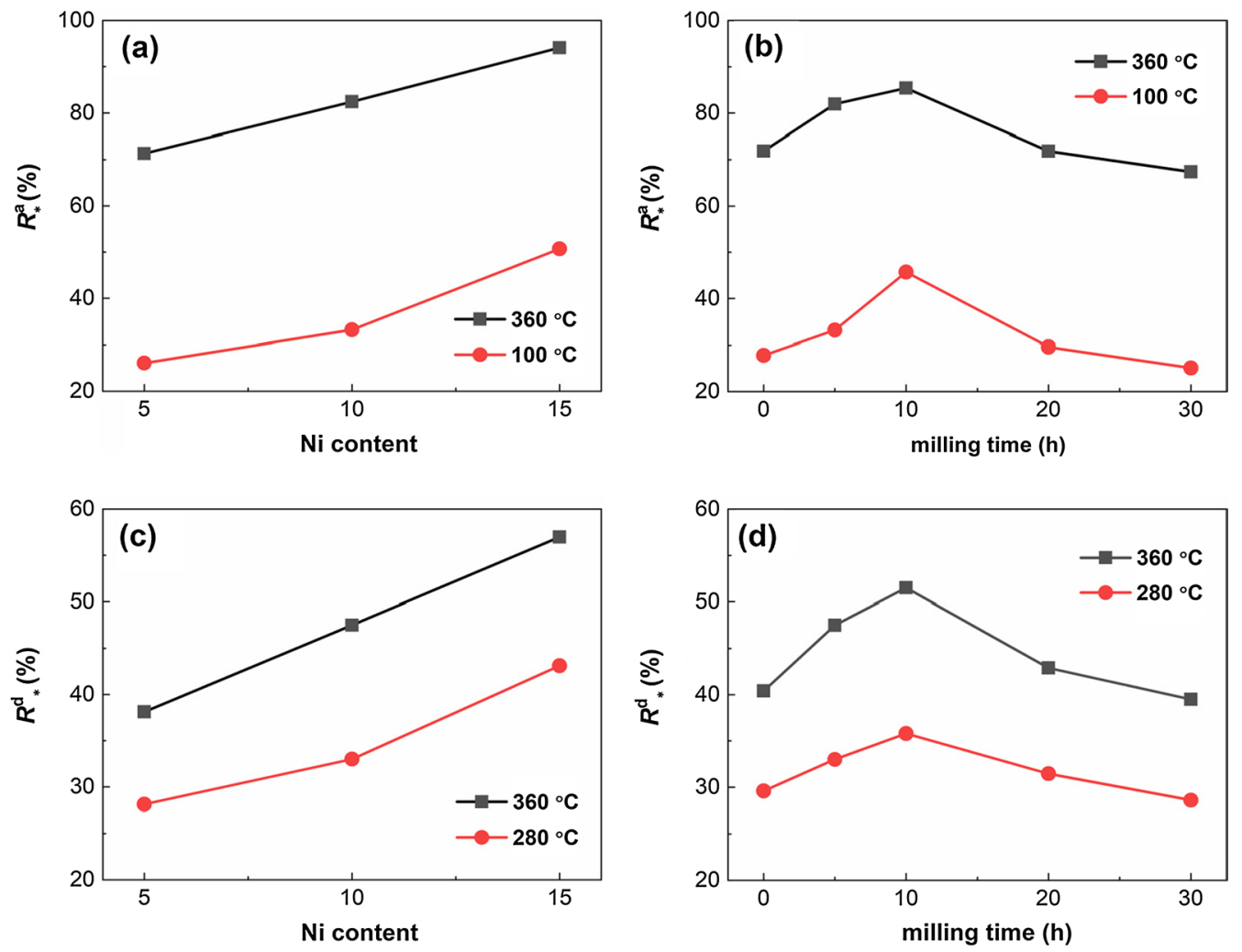

Fig. 6 Evolutions of the $R_{*}$ and $R_{*}^{\mathrm{d}}$ values of the as-milled $\mathrm{La}_{5} \mathrm{Mg}_{95-x} \mathrm{Ni}_{x}(x=5,10,15)$ alloys: a Ni5, Ni10, Ni15 alloys milled for $5 \mathrm{~h}$ at $360{ }^{\circ} \mathrm{C}$ and $100{ }^{\circ} \mathrm{C}$; b Ni10 alloys with different milling

times at $360{ }^{\circ} \mathrm{C}$ and $100{ }^{\circ} \mathrm{C}$; c Ni5, Ni10, Ni15 alloys milled for $5 \mathrm{~h}$ at $360{ }^{\circ} \mathrm{C}$ and $280{ }^{\circ} \mathrm{C}$; d Ni10 alloys with different milling times at $360{ }^{\circ} \mathrm{C}$ and $280{ }^{\circ} \mathrm{C}$

to be $78.4 \mathrm{~kJ} / \mathrm{mol}$ for as-cast, $77.0 \mathrm{~kJ} / \mathrm{mol}$ for $5 \mathrm{~h}, 72.1 \mathrm{~kJ} / \mathrm{mol}$ for $10 \mathrm{~h}, 77.8 \mathrm{~kJ} / \mathrm{mol}$ for $20 \mathrm{~h}$ and $78.5 \mathrm{~kJ} / \mathrm{mol}$ for $30 \mathrm{~h}$ and the $\Delta S$ values are calculated to be $139.5 \mathrm{~J} / \mathrm{mol} / \mathrm{K}$ for as-cast, $134.8 \mathrm{~J} / \mathrm{mol} / \mathrm{K}$ for $5 \mathrm{~h}, 123.2 \mathrm{~J} / \mathrm{mol} / \mathrm{K}$ for $10 \mathrm{~h}, 135.3 \mathrm{~J} / \mathrm{mol} / \mathrm{K}$ for $20 \mathrm{~h}$ and $135.6 \mathrm{~J} / \mathrm{mol} / \mathrm{K}$ for $30 \mathrm{~h}$. It can be seen that Ni10 milled for $10 \mathrm{~h}$ has the lowest $\Delta H$ and $\Delta S$ value and the best thermodynamic properties. It can be seen that the $\Delta H$ values for the alloys are slightly lower than $-78.6 \mathrm{~kJ} / \mathrm{mol}$ of pure $\mathrm{Mg}[33,34],-82.1 \mathrm{~kJ} / \mathrm{mol}$ of the $\mathrm{Mg}-\mathrm{Ni}-\mathrm{La}$ composite powders (Mg:Ni:La $=85: 10: 5$, in weight ratio) [35], $-76.12 \mathrm{~kJ} / \mathrm{mol}$ of $\mathrm{PrMg}_{11} \mathrm{Ni}$ [36], close to $-74.0 \mathrm{~kJ} / \mathrm{mol}$ of $\mathrm{Mg}-5 \mathrm{Ni}-3 \mathrm{Ni}$ (at.\%) [37]. With the rising of milling time, the $\Delta H$ and $\Delta S$ of as-milled Ni10 alloys reduce firstly and then increase. This trend is mainly due to the adjustment of the microstructure of the alloys by ball milling process. It causes polycrystalline structures to transform into nanocrystalline and amorphous structures. The amounts of nanocrystals will increase firstly and then decrease when milling time prolongs. When the milling time extends to $10 \mathrm{~h}$, the alloys are mainly composed of nanocrystalline phases with a large amount of sub-grain boundaries, which can improve the thermodynamic properties. However, further prolongation of milling time leads to the decrease in nanocrystalline phase and increase in amount of amorphous phase. The chemical

activity at the interface is high, and the $\mathrm{Mg}-\mathrm{H}$ bonds are weakened. Therefore, the $\Delta H$ and $\Delta S$ of Ni10 alloy milled for $10 \mathrm{~h}$ with a large number of grain boundary structures are proved to be the lowest, and its thermodynamic stability is also slightly adjusted. It means the alloying and ball milling enhance the thermodynamic properties.

\section{Conclusions}

The effects of Ni content and ball milling time on the hydrogen storage thermodynamics and kinetics of as-milled $\mathrm{La}_{5} \mathrm{Mg}_{95-x} \mathrm{Ni}_{x}(x=5,10,15)$ ternary alloys which are fabricated by vacuum induction melting have been systematically studied. The results can be summarized as the following conclusions:

(1) The as-milled Ni5, Ni10, Ni15 alloys are all based on $\mathrm{La}_{2} \mathrm{Mg}_{17}$ as the main phase, $\mathrm{Mg}_{2} \mathrm{Ni}$ and $\mathrm{Mg}$ as the second phases. The amount of $\mathrm{Mg}_{2} \mathrm{Ni}$ phase increased, while the $\mathrm{Mg}$ phase decreased with the rising of $\mathrm{Ni}$ content. Moreover, as the milling time is extended, the diffraction peak of $\mathrm{La}_{2} \mathrm{Mg}_{17}$ phase is gradually broadened, but the diffraction peak of the $\mathrm{Mg}_{2} \mathrm{Ni}$ phase 

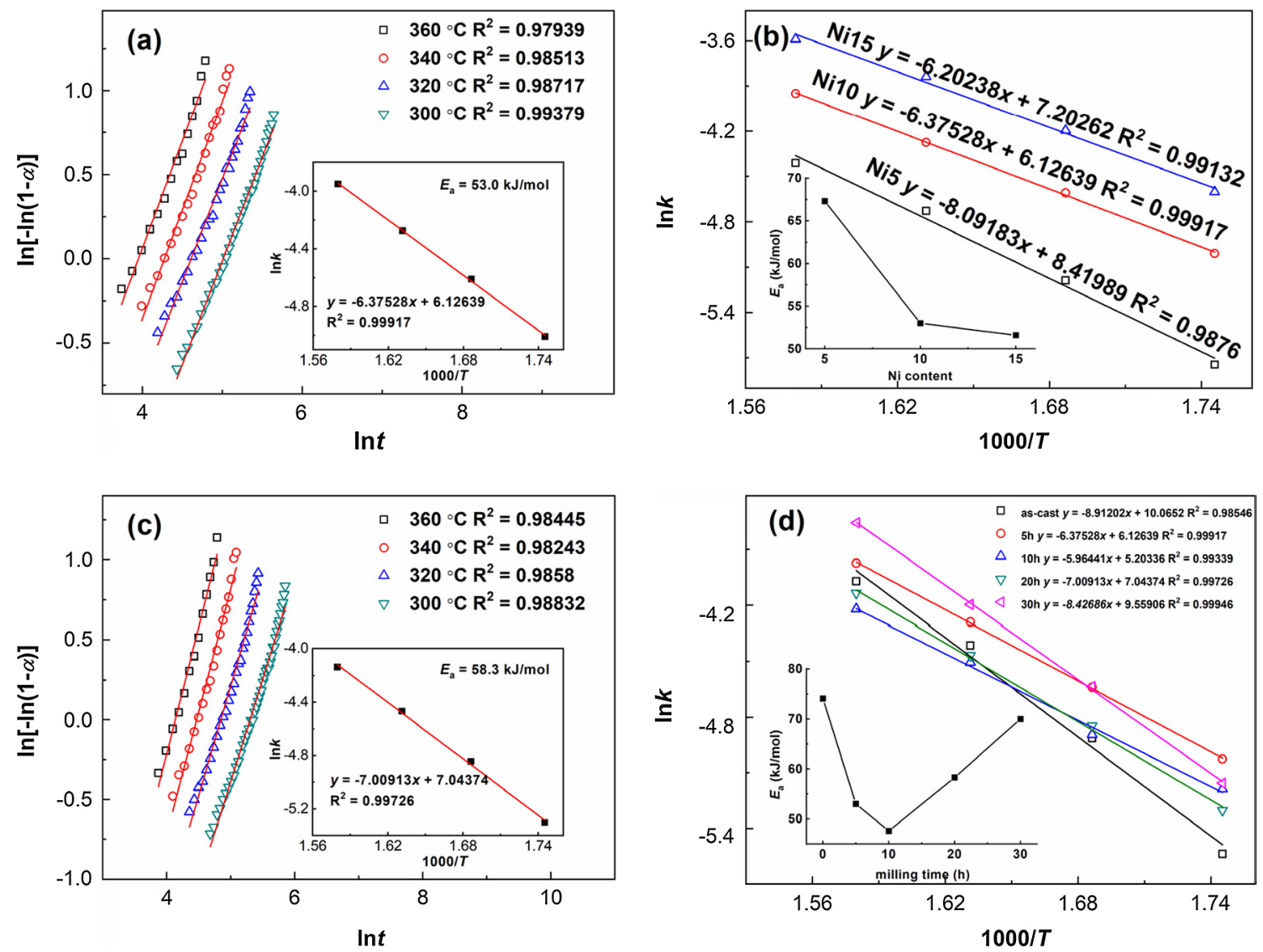

Fig. 7 JMA plots of $\ln [-\ln (1-\alpha)]$ versus $\ln t$ and Arrhenius plots of as-milled $\mathrm{La}_{5} \mathrm{Mg}_{95-x} \mathrm{Ni}_{x}(x=5,10,15)$ alloys: a Ni10 alloy milled for 5 h; b Ni5, Ni10, Ni15 alloys milled for 5 h; $\mathbf{c}$ Ni10 alloy milled for 20 h; $\mathbf{d}$ Ni10 alloys with different milling times

remained stable. With the action of ball milling, the generation of nanocrystalline structure has a positive effect on improving the kinetics and thermodynamics of hydrogen absorption and desorption of hydrogen storage materials.

(2) With more than six activation cycles, it is found that the rising of $\mathrm{Ni}$ content in this range remarkably improves the hydrogen storage kinetic, but reduces hydrogen storage capacity of as-milled alloys. And the $E_{\text {a }}$ value of hydrogen evolution decreases firstly and then increases with the rising of milling time, the minimum value is $47.6 \mathrm{~kJ} / \mathrm{mol}$, and the corresponding milling time is $10 \mathrm{~h}$.

(3) By means of PCI curves and van't Hoff equation, it indicates that the thermodynamic properties increase firstly and then decrease with the rising of $\mathrm{Ni}$ content in this range which is due to the proper mixing ratio, the microstructure of the as-milled alloys and the presence of the rare earth hydride. And with the increase in ball milling time, the $\Delta H$ and $\Delta S$ of as-milled Ni10 alloy decrease firstly and then increase. This trend is mainly due to the adjustment of the microstructure of the alloy by ball milling. 

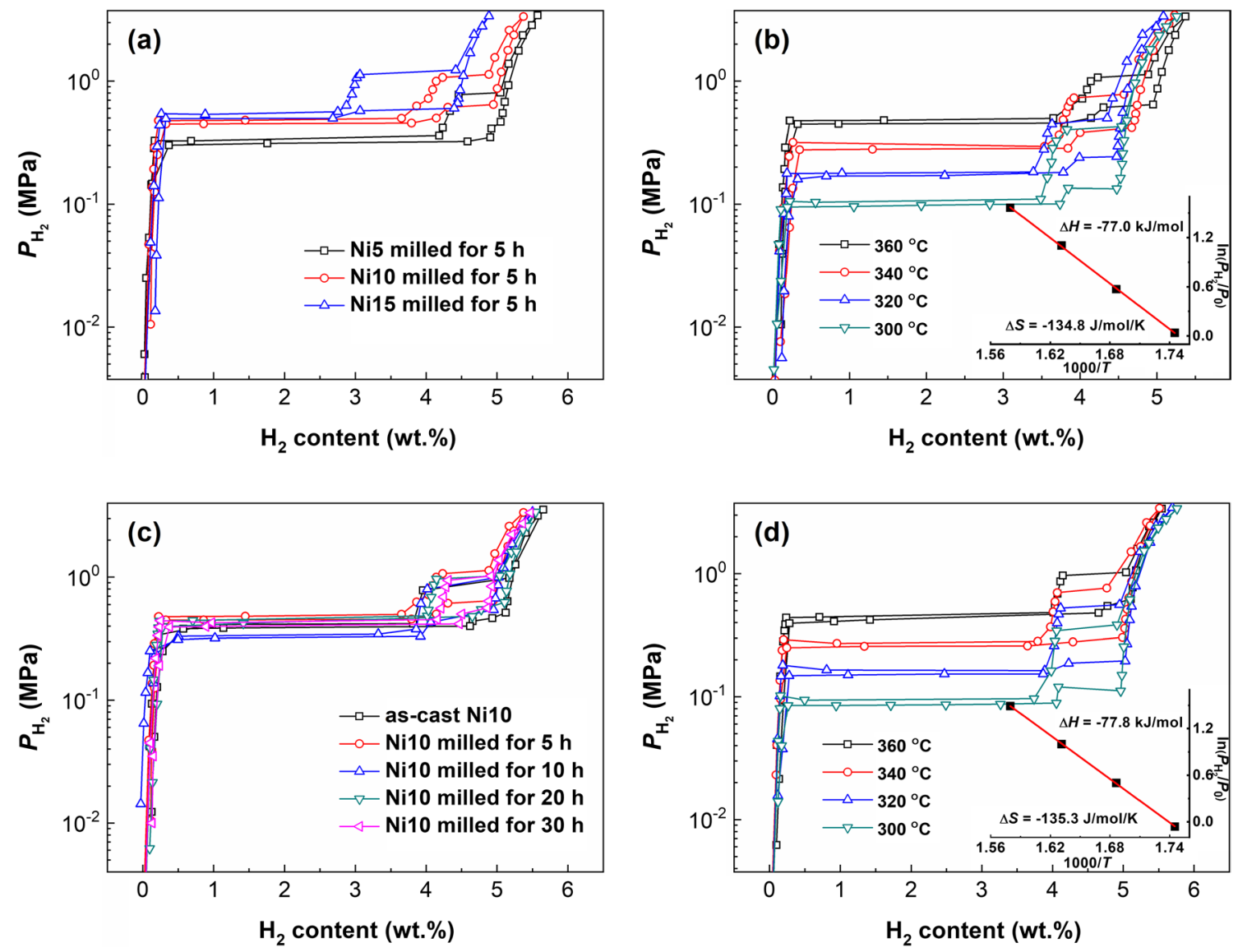

Fig. $8 \mathrm{P}-\mathrm{C}-\mathrm{I}$ curves of the as-milled $\mathrm{La}_{5} \mathrm{Mg}_{95-x} \mathrm{Ni}_{x}(x=5,10,15)$ alloys: a Ni5, Ni10, Ni15 alloys milled for $5 \mathrm{~h}$ at $360{ }^{\circ} \mathrm{C}$; $\mathbf{b} \mathrm{Ni10}$ alloy milled for $5 \mathrm{~h}$; c Ni10 alloys with different milling times at $360{ }^{\circ} \mathrm{C}$; $\mathbf{d}$ Ni10 alloy milled for $20 \mathrm{~h}$
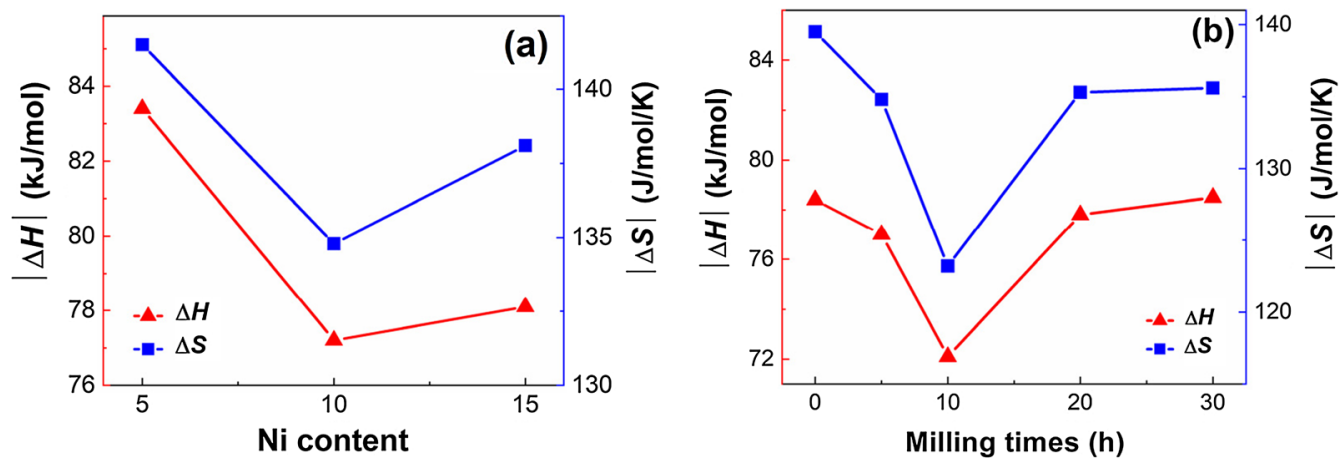

Fig. 9 Variations of the $\Delta H$ and $\Delta S$ absolute values of the hydrogen desorption reactions of as-milled $\operatorname{La}_{5} \mathrm{Mg}_{95-x} \mathrm{Ni}_{x}(x=5,10,15)$ alloys: a Ni5, Ni10, Ni15 alloys milled for 5 h; b Ni10 alloys with different milling times

Acknowledgements This work is financially supported by the National Natural Science Foundations of China (51761032, 51471054 and 51871125).

\section{References}

[1] B.X. Dong, J.J. Gao, Y.L. Teng, H. Tian, L.Z. Wang, Int. J. Hydrogen Energy 41, 5371 (2016)

[2] V. Shukla, A. Bhatnagar, S.K. Pandey, R.R. Shahi, T.P. Yadav, M.A. Shaz, O.N. Srivastava, Int. J. Hydrogen Energy 40, 12294 (2015)

[3] M. İskender, M. Atiş, J. Alloys Compd. 667, 275 (2016) 
[4] Y.M. Li, B.Y. Duan, Z.C. Liu, Y.H. Zhang, H.P. Ren, Acta Metall. Sin. (Engl. Lett.) 31, 897 (2018)

[5] Z. Wu, Z.X. Zhang, F.S. Yang, P.H. Feng, Y.Q. Wang, Int. J. Hydrogen Energy 41, 2771 (2016)

[6] M. Anik, F. Karanfil, N. Küçükdeveci, Int. J. Hydrogen Energy 37, 299 (2012)

[7] Y.B. Pan, H.Y. Leng, W. Jia, Q. Li, Int. J. Hydrogen Energy 38, 10461 (2013)

[8] I.P. Jain, C. Lal, A. Jain, Int. J. Hydrogen Energy 35, 5133 (2010)

[9] Z.J. Cao, L.Z. Ouyang, Y.Y. Wu, H. Wang, J.W. Liu, F. Fang, D.L. Sun, Q.G. Zhang, M. Zhu, J. Alloys Compd. 623, 354 (2015)

[10] Z.M. Yuan, W. Zhang, P.L. Zhang, Y.H. Zhang, W.G. Bu, S.H. Guo, D.L. Zhao, Rsc Adv. 7, 56365 (2017)

[11] Y.H. Zhang, W. Zhang, J.L. Gao, Z.M. Yuan, W.G. Bu, Y. Qi, Acta Metall. Sin. (Engl. Lett.) 30, 1010 (2017)

[12] T. Spassov, U. Köster, J. Alloys Compd. 287, 243 (1999)

[13] H. Oesterreicher, H. Bittner, J. Less-Common Met. 73, 339 (1980)

[14] T. Kohno, H. Yoshida, F. Kawashima, T. Inaba, I. Sakai, M. Kanda, J. Alloys Compd. 311, L5-L7 (2000)

[15] Y.H. Zhang, Z.M. Yuan, W.G. Bu, F. Hu, Y. Cai, D.L. Zhao, Acta Metall. Sin. (Engl. Lett.) 29, 1 (2016)

[16] L.S. Xie, J.S. Li, T.B. Zhang, H.C. Kou, Renw. Energy 113, 6118 (2017)

[17] Y.H. Zhang, T. Yang, W.G. Bu, Y. Cai, G.F. Zhang, D.L. Zhao, T. Nonferr. Metal. Soc. 23, 3668 (2013)

[18] Q.A. Zhang, C.J. Jiang, D.D. Liu, Int. J. Hydrogen Energy 37, 10709 (2012)

[19] S. Kalinichenka, L. Röntzsch, T. Riedl, T. Weißgärber, B. Kieback, Int. J. Hydrogen Energy 36, 10808 (2011)

[20] S. Kalinichenka, L. Röntzsch, T. Riedl, T. Gemmingc, T. Weißgärber, B. Kieback, Int. J. Hydrogen Energy 36, 1592 (2011)
[21] S. Kalinichenka, L. Röntzsch, C. Baehtz, B. Kieback, Int. J. Hydrogen Energy 496, 608 (2010)

[22] G. Hao, Y.F. Zhu, L.Q. Li, Int. J. Hydrogen Energy 33, 2970 (2008)

[23] Y.J. Lv, B. Zhang, Y. Wu, J. Alloys Compd. 641, 176 (2015)

[24] J.G. Yuan, N. Xing, Y. Wu, Int. J. Hydrogen Energy 42, 6118 (2016)

[25] Y.H. Zhang, Z.M. Yuan, W.G. Bu, H. Feng, Y. Cai, D.L. Zhao, Acta Metall. Sin. (Engl. Lett.) 29, 577 (2016)

[26] H.W. Shang, Y.H. Zhang, Y.Q. Li, Y. Qi, S.H. Guo, D.L. Zhao, Int. J. Hydrogen Energy 43, 1691 (2018)

[27] S.S. Liu, L.X. Sun, Y. Zhang, F. Xu, J. Zhang, H.L. Chu, M.Q. Fan, T. Zhang, X.Y. Song, J.P. Grolier, Int. J. Hydrogen Energy 34, 8079 (2009)

[28] C.Z. Wu, P. Wang, X. Yao, C. Liu, D.M. Chen, G.Q. Lu, H.M. Cheng, J. Alloys Compd. 420, 278 (2006)

[29] H.L. Chu, S.J. Qiu, Q.F. Tian, L.X. Sun, Y. Zhang, F. Xu, Y.Y. Liu, Y.N. Qi, M.Q. Fan, Int. J. Hydrogen Energy 32, 4925 (2007)

[30] Y.H. Zhang, L.W. Li, D. Feng, P.F. Gong, H.W. Shang, S.H. Guo, T. Nonferr. Metal. Soc 27, 551 (2017)

[31] X.F. Liu, Y.F. Zhu, L.Q. Li, Intermetallics 15, 1582 (2007)

[32] B. Vigeholm, J. Kjøller, B. Larsen, J. Less-Common Met. 74, 205 (1980)

[33] J.F.S. Jr, C.E.H. Jr, J.F. Suttle, J. Am. Chem. Soc. 82, 3504 (1960)

[34] B. Vigeholm, J. Kjøller, B. Larsen, J. Less-Common Met. 74, 205 (1980)

[35] J.X. Zou, H. Guo, X.Q. Zeng, S. Zhou, X. Chen, W.J. Ding, Int. J. Hydrogen Energy 38, 8852 (2013)

[36] Y.H. Zhang, Y.Q. Li, H.W. Shang, Z.M. Yuan, Y. Cai, Y. Qi, D.L. Zhao, Int. J. Hydrogen Energy 42, 22379 (2017)

[37] B. Zhang, Y.J. Lv, J.G. Yuan, Y. Wu, J. Alloys Compd. 702, 126 (2017) 